\title{
The Impact of Cash Flow Volatility on Cash-Cash Flow Sensitivity
}

\author{
UmairTahir, NaeemUllah \\ Master of Business Administration in Finance Foundation University Institute of Engineering \& Management \\ Sciences New Lalazar, Rawalpindi Cantt. Pakistan \\ Assistant Professor at Department of Management Sciences Foundation University Institute of Engineering \& \\ Management Sciences New Lalazar, Rawalpindi Cantt. Pakistan
}

\begin{abstract}
This study was conducted to learn the impact of cash flow volatility on firm's cash holdings. The result indicated a positive significant coefficient for cash flow and cash flow volatility while leverage had negative and significant coefficient. The study concludes that firms facing risk tends to hold more cash out of there cash flow. All the results obtained by us are in line with the literature available on cash to cash flow sensitivity.
\end{abstract}

Keywords: market, organizations, cash flow, cash holdings, corporate sectors.

Paper type: Research paper

\section{Introduction}

In financial materials, corporate financial commitments have been researched a lot. Many empirical reports are also done. This managing routines are viewed as just as one essential element of the actual intangible organizational capital. In the earlier financial materials, a couple main hypotheses are projected so as to outline the corporate expense misrepresentation. The first evidence is usually in which operators remain deal for the reputation of the situations associated with awareness among investors and managing. Mangers also overinvest in order to flourish their own business owners and in the in an identical way that they test to run away through the management and that is employed in excess of these people. The 2nd motive is usually in which irregularity associated with details will caused problems associated with funding and cause the healthiness of underinvestment associated with corporation.

While using the issues, agency difficulty as well as irregularity involving info, the actual financial commitment depends upon cash framework. These own explanations by analysts refer to the actual existence involving expenditure cash flow awareness. The agency hypothesis suggests that supervisors involving company may boost the expenditure levels and also the ease of access involving internal cash flow for your motive to escape from the market place handle. In the event that it will have sufficient internal cash flow, the actual expenditure are going to be greater and also the chance of expenditure misrepresentation also are greater. While using the other hypothesis involving asymmetric info, supervisors involving company may limit the actual outer money; consequently the actual expenditure will be based on when internal money resiliently.

This financial flexibility can be a capability of company in order to tactic the lowest capital cost. Additionally, the way the company responds in order to sudden changes in the company funds passes or perhaps investment opportunities in an ideal approach. Additionally financial flexibility is known as seeing that an important influential part of corporate financial plans, in a very review connected with CFO's in (Graham \& Harvey, 2001). Although until finally very lately, the idea is not researched as a 1st order influential part of corporate financial plans.

Based on (Easterbrook, 1984) in addition to (Jensen, 1986)the particular part involving payment procedures which is a major area of the theoretical management and business fund, continues to be highlighted, in working with agency conflicts involving the management and business insiders in addition to exterior shareholders. The primary indisputable fact that the earnings are certainly not paid for to help shareholders can be abstracted by means of insiders in their own advantage. For example, business professionals may possibly assign these kinds of finances to help those tasks that develop personal advantages for them to loosing exterior shareholders. Based on (Jensen, 1986)this kind of conflict around payment procedures can be very strict while businesses maintain substantial degrees of free of charge earnings, that's, while money inflows significantly rise above the particular skilled reinvestment requires or maybe prospects. Though considering funds areas, that happen to be performance perfectly, this kind of conflict might quickly end up being resolved without the need of upsetting have an effect on shareholder value. Certainly, businesses can fund the investment decision by means of issuing explains to you in addition to assign to share away each of their profits to help exterior shareholders, in this way zero money could well be abstracted or maybe wasted by means of management and 
business insiders. Working expenses in addition to new investment decision charges might merely end up being satisfied by means of issuing new explains to you.

The relative in between profit volatility and also expenditure and also succeeding profit and also profits level is predicted inside the practices connected with underinvestment. Even though thinking about these types of practices trusted, the outcome chosen of which forecasting versions of which encompass volatility to be a illustrative changing get larger perfection and also decrease partiality then your forecasting versions of which get rid of volatility. Once the company is quite possibly to undergo underinvestment, your advancement inside forecast perfection and also tendency is larger. According to these types of information, it is offered of which equity market allies do not consist of completely the data inside traditional volatility while forecasting potential company effectiveness.

\section{Literature Review}

In an agency a new manager's significant stage connected with fascination is the generating money readily available for extended funding. In accordance with (Modigiliani \& M.H Miller, 1966), there is absolutely no variance between your costs connected with personal source and central and outer money, in times of any comprehensive investment capital market place. On this circumstance, through investment capital marketplaces along with a sturdy investment capital expenditure, money could be furnished by corporation.

Whilst talking in practice, it can be observed of which capital industry cannot be fully proficient or perhaps useful. Since on a single stop, the administrators control the corporation that are not just the owners and could get relatively distinct advantages while compare for the owners in the businesses. Throughout such a scenario, traders obtain more production in order to fiscally supply the investment assignments while they do not hold the identical have confidence in while administrators.

According to (Modigiliani \& M.H Miller, 1966), inside nonexistence of marketplace unpredictability, the financial and also investment choices are viewed independent. The last scientific tests revealed it is this market unpredictability making for costlier after those regional funds.

Within the study cardstock of (A.Minton \& M.Schrand), It truly is noted of which earnings volatility can be related to reduced numbers of expense in funds expenses, study and growth and promotion. For that reason companies tend not to bend over in direction of exterior funds markets to fully hide earnings damage. Whilst thinking of this kind of realization, it truly is noted of which companies using higher cost of funds industry admittance, the level of responsiveness of expense for you to earnings volatility can be greater. Along with this, earnings and profits volatility usually are related to this kind of higher cost. As a result, it truly is figured volatility not merely increases the chances that this agency will require getting close to funds markets; it also boosts the price tag on doing this. Corporate chance administration theory claims of which investors tend to be much comfy when the agency can be continues up smooth cash passes. Based on (Froot, Scharfstein, \& Stein, 1993), by means of lowering your firm's addiction for the costly outside money, smooth profit could increase benefit.

With empirical study, (Minton \& Schrand, 1999) defined of which as a result of raise throughout the price tag on elevating outside funds, of which profit volatility can be costly the way it influences the firm's investment. Throughout exploration paper associated with (George Allayannis) concept can be tested that cash flow volatility along with getting have a negative influence on price of the company. While prior studies recommended that cash flow volatility can be high-priced. Throughout distinct, it is often found that cash flow volatility can be significantly along with negatively related to the worth of the company. The information confirmed the importance associated with possibility managing actions which usually more planned in decreasing potential cash flow volatility. In this particular exploration, there is a significant difference on the prior studies, which usually offers that supervisors on the company target their actions in generating even dollars flows rather than related to on their own fundamentally along with reporting even revenue with accrual rates.

Based on a work connected with (J. Campbell \& Schwartz) it had been recorded that will variance in the price of outside money include the main reason behind investment cash flow sensitivities. Also it had been demonstrated that will cash flow volatility has a significant part inside modify connected with the price of the actual outside money as well as investment cash flow sensitivities.

Within the study regarding (Saiyid S.Islam) the impact regarding monetary progress about the level of responsiveness regarding firm-level purchase to be able to internal earnings is actually looked at. Within the research, by 1987-1997 by in relation to thirty-one international locations intercontinental info is utilized. With time frame regarding results, it had been discovered that those international locations that had been a smaller amount monetarily created are more vulnerable to be able to earnings. Which confirmed that international locations possessing a smaller amount usage of external capital suffer from more expensive regarding details troubles? And with this, the outcomes furthermore confirmed that international locations having poor standards regarding monetary data processing may very well deal with larger troubles although being able to access 
external capital market segments. These kinds of businesses generally suffer from excessive below purchase price tag and additional leads to a rather slower fiscal progress for the nation.

Lots of research has been done within realizing the actual elements which management and business expense and financial stability can be inspired simply by monetary marketplace imperfections. (Mairesse \& Dormont, 1985)shown a new comparison expense evaluation in France, Ought $\mathrm{S} \&$ Belgium big organization regarding the timeframe of 1970-1979. The actual result ended up being located which in a variety of international locations the actual expense behavior ended up being equivalent. So that it ended up being important to discover exactly why with the distinctions in between international locations within response to profit.

According to (Cleary, 2006) profit volatility may very well be in a wrong way connected to be able to expense profit sensitivities. He or she in addition mentioned which profit volatility can be intrinsically connected to be able to monetary stability.

In the document involving (Klaas Mulier), it truly is discussed in which earnings volatility leads to terminology involving showing in the earnings annoyed. For a selected earnings annoyed, an opportunity may be that this would likely reveal the particular company along with decrease earnings volatility for the reason that chance is larger for them that this earnings annoyed fall above outside the regular earnings instability. Along with this, these are probably to switch the leads concerning foreseeable future earnings. This means that organizations along with minimal earnings volatility, the particular require pertaining to outer financing will certainly fall. Consequently the expense of outer financing will certainly fall much more. Companies while using the greatest fall throughout the expense of outer financing will certainly assist in more purchase, and so organizations along with minimal earnings volatility will show the largest motivator to get. It truly is figured the lower earnings volatility is linked to increased purchase earnings tenderness. In the investigation, empirical examination has become done throughout six places which usually approve in which purchase earnings the like usually are larger pertaining to organizations along with minimal earnings volatility.

From the investigation paper of Laurence Cubicle in addition to (Cleary, 2006), cash flow volatility in addition to economic slack is known as being a significant function. It is additionally mirrored that will during the lifestyle of economic restrictions, the way cash flow volatility in addition to economic slack interrelate to effect expense cash flow breathing difficulties. Also a theoretical product is demonstrated that will explain organization expense selections while confronted by market restrictions. Also a big impartial small sample of you.Azines companies on the period of 1981 to 1998 were looked at. Also the outcomes Okayed that will cash flow volatility incorporate a significant in addition to sturdy influence on the number of economic slack. It had been found that will companies along with large cash flow volatility continue in the highest degrees of economic slack. Also those firm's expense fees tend to be a lesser amount of vulnerable to the firm's internally created cash runs.

From the study connected with (Bernadette A. Minton) it is explained in which even with coping with to the expenses connected with being able to view outer capital, earnings volatility stays on a serious negative determinant connected with purchase. Also, earnings volatility improves these kinds of expenses. In this cardstock, it absolutely was figured businesses don't entirely easy earnings volatility through the perfect time to maintain purchase quantities but rather bypass some purchase. It turned out not really claimed in which effects imply that agency must reduce volatility. Quite, the effects connected with volatility signify 1 aspect that your agency should think within its possibility supervision options. Firms must decide on how to change your predicted negative impression connected with volatility with purchase quantities when compared from the some other outcomes connected with coping with volatility.

In the study regarding (Javad Moradi), it really is offered there is a large relation between range of motion inside money along with inside investment decision. The results furthermore explain that the relation is positive and as well income volatility associate together with changes inside investment decision circumstances. It is usually recommended of which supervisors need to concentrate on balancing money moves along with assets. The excuse is when presently there could be the greater assets then the firm's ability; this might cause the particular company in direction of individual bankruptcy.

From the analysis of (Tao Chen, 2013), your quickly arranged side effects of personal versatility with dollars guidelines of U.S firms are usually looked at. Robust proof seemed to be observed of which increases with property beliefs direct in direction of scaled-down corporate dollars stores, drop in the minor value of dollars holdings, and also reduce income the like of dollars. It had been observed that this loss of dollars holdings is a lot more different with company, using higher investment decision prospects, personal constraints and also greater corporate governance.

Within the paper of (Jean Paul Decamps, 2007), Issuance as well as payout policy is usually studied that improves the importance of your company struggling with each organization costs of no cost income as well as outside funding costs. It turned out observed that businesses get goal cash quantities and quite a few advantageous issue values if they get little cash. Accomplishing this is usually demonstrated, which represents 
the quantity of exceptional gives you plus the investment price ranges. It is exhibited that following a negative distress on investment price ranges, the two volatility of investment dividend plus the dollar volatility of investment price ranges blow up.

Within the paper connected with (Armen Hovakimian \& Hovakimian, 2005) ,the actual regards involving investment decision fees and also in the camera generated funds streams is actually evaluated applying firm-level estimates connected with investment decision cash flow level of sensitivity. In addition to this it is screened no matter if high level of sensitivity is actually related with monetarily key modifications with company investment decision and also funding habits. It really is observed the cash flow delicate companies are generally in financial terms restricted and also underinvested with small cash flow a long time, however are certainly not restricted and also overinvest with high cash flow a long time. The actual supply connected with external money is actually really linked together with funds streams, escalating investment decision cash flow level of sensitivity. Administrators strongly balanced out the actual variance with central and also external liquidity by having functioning money any time liquidity is actually high and also depleting it any time liquidity is actually small. Whilst personal restrictions offer an monetarily key affect investment decision timing, cash flow delicate companies reduce their results and actually overinvest in complete.

Inside the study associated with (Sehrish Ahsan \& Ullah, 2013), panel files associated with 377 creation organizations listed on Karachi Stock exchange is considered so as to observe the influence associated with income volatility on cash in order to income level of responsiveness associated with Pakistani organizations. Your testing on files confirmed that will income volatility features a important effect on cash in order to income level of responsiveness. Your organizations were being broken down in minimal and unconstrained kinds by employing income volatility and size. Your organizations that had been classified depending on income volatility confirmed effects that will income level of responsiveness is more because of extended culpability for minimal organizations and because of revenue expansion for unconstrained organizations. Additionally, the organizations that had been classified depending on size confirmed the outcomes that will cash in order to income level of responsiveness is present with both equally minimal and unconstrained organizations.

\section{Methodology}

\subsection{Data:}

The data for different variables used in our study are obtain from balance sheet analysis publish by state bank of Pakistan from 2005 to 2010.The estimating period is ideal because during these five years Pakistani economy went through different stages of economic cycle. Only those firms will be taken in our data whose information is available throughout the estimation period. Further we will keep only those firms that survive winsorizing that will be carried out in order to remove heteroskedasticity from our data. As a result of this 200 firm taken in our study only 101 firms remain in our sample.

\subsection{Regression Model}

The following baseline regression model will be used be used to estimate the impact of cash flow volatility on cash to cash flow sensitivity.

Cash holding $=\infty+\beta_{1}(\mathrm{cf})_{\mathrm{i}, \mathrm{t}}+\beta_{2}(\mathrm{Tq})_{\mathrm{i}, \mathrm{t}-1}+\beta_{3}(\text { size })_{\mathrm{i}, \mathrm{t}-1}+\beta_{4}(\text { cash volt })_{\mathrm{i}, \mathrm{t}}+\beta_{5}(\mathrm{lev})_{\mathrm{i}, \mathrm{t}}+(\text { year effect })_{\mathrm{i}, \mathrm{t}}+\mathrm{E}_{\mathrm{i}, \mathrm{t}}$

Whereas:

$\mathrm{Cf}=$ Cash flow

$\mathrm{Tq}=$ Tobin's Q

Cash volt $=$ Cash volatility

Lev= Leverage

\section{Panel data regression model}

We entertain to estimate along term relationship among variables by using the common effect model, fixed effect model and random effect mode

\subsubsection{Common effect model}

Underline assumption under these techniques is homogeneity of cross sectional units. The following common effect model will be estimated for our study

Cash holding $=\alpha_{0}+\beta_{1}(\mathrm{cf})_{\mathrm{i}, \mathrm{t}}+\beta_{2}(\mathrm{Tq})_{\mathrm{i}, \mathrm{t}-1}+\beta_{3}(\text { size })_{\mathrm{i}, \mathrm{t}-1}+\beta_{4}(\text { cash volt })_{\mathrm{i}, \mathrm{t}}+\beta_{5}(\text { lev })_{\mathrm{i}, \mathrm{t}}+(\text { yeareffect })_{\mathrm{i}, \mathrm{t}}+\mathrm{E}_{\mathrm{i}, \mathrm{t}}$

The disadvantage of this technique is the assumption of homogeneity has proven to be over simplistic. Since our firms belong to different industries, we may not produce generalizable result using common effect model. 


\subsection{2. $\quad$ Fixed effect model}

It is a powerful panel data estimation technique that adjusts for heterogeneity of cross-sectional units. We will estimate the following fixed effect regression model

Cash holding $=\alpha_{\mathrm{i}}+\beta_{1}(\mathrm{cf})_{\mathrm{i}, \mathrm{t}}+\beta_{2}(\mathrm{Tq})_{\mathrm{i}, \mathrm{t}-1}+\beta_{3}(\text { size })_{\mathrm{i}, \mathrm{t}-1}+\beta_{4}(\text { cashvolt })_{\mathrm{i}, \mathrm{t}}+\beta_{5}(\text { lev })_{\mathrm{i}, \mathrm{t}}+(\text { yeareffect })_{\mathrm{i}, \mathrm{t}}+\mathrm{E}_{\mathrm{i}, \mathrm{t}}$

Fixed model produces more robust and generalizable result then common effect model as it assumes separate intercept for cross sectional units and also it controls for the biases that may come due to omitted variable.

\subsubsection{Random effect model}

It controls for the biases caused by the error term. We will estimate the following random effect model

Cash holding $=\alpha_{0}+\beta_{1}(\mathrm{cf})_{\mathrm{i}, \mathrm{t}}+\beta_{2}(\mathrm{Tq})_{\mathrm{i}, \mathrm{t}-\mathrm{l}}+\beta_{3}(\text { size })_{\mathrm{i}, \mathrm{t}-\mathrm{l}}+\beta_{4}(\text { cashvolt })_{\mathrm{i}, \mathrm{t}}+\beta_{5}(\text { lev })_{\mathrm{i}, \mathrm{t}}+(\text { yeareffect })_{\mathrm{i}, \mathrm{t}}+\mathrm{E}_{\mathrm{i}, \mathrm{t}}$

\subsubsection{Haussmann test}

In case we get conflicting result from fixed and random effect model, we will conduct Haussmann test in order to select the best result for generalizable result.

The housemen test will be carried out under the following hypothesis

$\mathrm{H} 1=$ Fixed effect test are accepted

$\mathrm{H} 0=$ Random effect test are accepted

If we get a (p) value 0.05 or less we will accept fixed effect model and vice versa.

\section{Results and discussions:}

\subsection{Descriptive statistics:}

$\underline{\text { Table-1 }}$

\begin{tabular}{|c|c|c|c|}
\hline Variable & Obs & Mean & Std. Dev. \\
\hline cash & 404 & 0.154736 & 0.317682 \\
\hline cf & 404 & 0.253756 & 0.730477 \\
\hline tq & 404 & 0.637598 & 0.458657 \\
\hline size & 404 & 14.84831 & 1.249254 \\
\hline cashvolt & 404 & 0.115084 & 0.322243 \\
\hline lev & 404 & 0.615808 & 0.202327 \\
\hline
\end{tabular}

Table-1 represents the descriptive statistic of our study.It is clear from our table that we obtain 404 firm air observations for every variable of our study. The mean of cash holding is 15.47 percent while that of cash flow is 25.4 percent while the cash volatility is a mean of 11.5 percent while that of leverage is 61.5 percent The descriptive statistics indicate that a high percent of cash holding occurs as cash volatility increases. Further the cash flow has a mean of 25 percent as against the mean of cash holding 15 percent. This indicates that Pakistani firms are holding more firms out of their operational cash flow.

\subsection{Correlation matrix:}

Table-2

\begin{tabular}{|l|r|r|r|r|r|r|}
\hline & cash & cf & tq & size & cashvolt lev \\
\hline cash & 1.00 & & & & & \\
\hline cf & -0.01 & 1.00 & & & & \\
\hline tq & -0.18 & 0.13 & 1.00 & & & \\
\hline size & 0.01 & 0.14 & -0.06 & 1.00 & & \\
\hline cashvolt & 0.35 & -0.48 & -0.03 & -0.04 & 1.00 & \\
\hline lev & -0.36 & -0.06 & 0.48 & -0.04 & -0.18 & 1.00 \\
\hline
\end{tabular}

Table-2 represents the correlation matrix of our variables used in the study. It can be clearly seen from the table that there is no significant correlation among our independent variables. Thus our data is free from the problem of multicollinearity. 


\subsection{Common effect model:}

$\underline{\text { Table-3 }}$

\begin{tabular}{|l|r|r|r|r|r|r|}
\hline cash & Coef. & Std. Err. & \multicolumn{1}{c|}{$\mathrm{t}$} & & $\mathrm{P}>\mathrm{t}$ & \multicolumn{2}{c|}{ [95\% Conf Interval] } \\
\hline cf & 0.178251 & 0.027881 & 6.39 & 0 & 0.123437 & 0.233065 \\
\hline tq & -0.09886 & 0.035739 & -2.77 & 0.006 & -0.16912 & -0.0286 \\
\hline size & -0.00944 & 0.011043 & -0.85 & 0.393 & -0.03115 & 0.012271 \\
\hline cashvolt & 0.580555 & 0.062518 & 9.29 & 0 & 0.457646 & 0.703465 \\
\hline lev & -0.2489 & 0.0839 & -2.97 & 0.003 & -0.41385 & -0.08395 \\
\hline cons & 0.42622 & 0.173636 & 2.45 & 0.015 & 0.084854 & 0.767586 \\
\hline
\end{tabular}

Table-3 represents the result obtained by common effect model, fixed effect model and random effect model. The result of common effect model indicates significant positive coefficient for cash flow and cash flow volatility while Tobin's Q and leverage have significant coefficient but with negative signs.However as outlined in the methodology, these results are conducted under the assumptions of homogeneity of cross-sectional unit will prevent us to give generalizable results. Therefore we have performed random and fixed effect model for more generalizable and robustresult.

\subsection{Fixed effect model:}

Table-4

\begin{tabular}{|l|r|r|r|r|r|r|}
\hline cash & Coef. & Std. Err. & \multicolumn{1}{c|}{$\mathrm{t}$} & \multicolumn{2}{c|}{$\mathrm{P}>\mathrm{t}$} & \multicolumn{2}{l}{ [95\% Conf Interval] } \\
\hline cf & 0.013488 & 0.028278 & 0.48 & 0.634 & -0.04216 & 0.06914 \\
\hline tq & -0.01355 & 0.023294 & -0.58 & 0.561 & -0.0594 & 0.032293 \\
\hline size & 0.068465 & 0.042037 & 1.63 & 0.104 & -0.01426 & 0.151195 \\
\hline cashvolt & 0.201068 & 0.06414 & 3.13 & 0.002 & 0.074837 & 0.327299 \\
\hline lev & 0.039096 & 0.136779 & 0.29 & 0.775 & -0.23009 & 0.308281 \\
\hline cons & -0.88717 & 0.630016 & -1.41 & 0.16 & -2.12707 & 0.352726 \\
\hline
\end{tabular}

Table-4 shows the fixed effect model estimates a positive significant coefficient for cash flow volatility while it estimates insignificant coefficient for other variables of the study. The coefficient of operational cash flow is also insignificant however it is positive.

\subsection{Random effect model:}

$\underline{\text { Table-5 }}$

\begin{tabular}{|l|l|l|r|r|r|r|}
\hline cash & Coef. & Std. Err. & \multicolumn{1}{|c|}{ z } & P $>$ z & [95\% Conf Interval] \\
\hline cf & 0.072221 & 0.025557 & 2.83 & 0.005 & 0.02213 & 0.122313 \\
\hline tq & -0.01404 & 0.023646 & -0.59 & 0.553 & -0.06039 & 0.032305 \\
\hline size & 0.006781 & 0.017127 & 0.4 & 0.692 & -0.02679 & 0.040351 \\
\hline cashvolt & 0.337816 & 0.057823 & 5.84 & 0 & 0.224485 & 0.451148 \\
\hline lev & -0.24442 & 0.096342 & -2.54 & 0.011 & -0.43325 & -0.05559 \\
\hline cons & 0.182368 & 0.263802 & 0.69 & 0.489 & -0.33468 & 0.699411 \\
\hline
\end{tabular}

Table-5 show the random effect model is in line with the funding's of common effect model with some exceptions. Like common effect model, it assigns positive significant coefficients for cash flow and cash flow volatility. It assigns negative significant coefficient for leverage but the coefficient for Tobin's Q is insignificant but negative.

\subsection{Hausman test:}

We look at the results of fixed and random effect models one can easily infer that the results of both the models are not in alignment. Thus to select the best model, we will conduct hausman test. The result of hausman test is as follow: 


\begin{tabular}{|c|c|c|c|c|c|}
\hline & \multicolumn{3}{|c|}{---- Coefficients ---- } & & \\
\hline & (b) & (B) & $(b-B)$ & \multicolumn{2}{|c|}{ sqrt(diag(V_b-V_B)) } \\
\hline & fe & re & Difference & S.E. & \\
\hline cf & 0.0134882 & 0.0722214 & -0.058733 & 0.0121013 & \\
\hline tq & -0.0135511 & -0.0140405 & 0.0004894 & . & \\
\hline size & 0.0684653 & 0.0067813 & 0.061684 & 0.0383892 & \\
\hline cashvolt & 0.2010678 & 0.3378164 & -0.136749 & 0.0277571 & \\
\hline lev & 0.0390959 & -0.2444197 & 0.2835156 & 0.097091 & \\
\hline \multirow[t]{4}{*}{ Test: } & Ho: & \multicolumn{4}{|c|}{ difference in coefficients not systematic } \\
\hline & & $\operatorname{chi} 2(8)=$ & \multicolumn{3}{|c|}{$(b-B)^{\prime}\left[\left(V \_b-V \_B\right)^{\wedge}(-1)\right](b-B)$} \\
\hline & & $=$ & 14.26 & & \\
\hline & & Prob $>$ chi2 $=$ & 0.0752 & & \\
\hline
\end{tabular}

It is clear from the above that the hausman test has rendered a P-value of 0.0752 that indicates that we accept the results of random effect model.

\subsection{Results:}

Table-5 results shows the results of variables that show significantly and insignificantly positive and negative results

Cash flow (cf) show in the random effect model assigns the significant coefficient (P-value= $0.005<0.05)$ for operational cash flow. This clearly indicates thatPakistani firms are holding more cash out of their operational cash flows. There result are in alignment with Almeida et al (2004), they also found the evidence that firm tends to hold more cash out of their operational cash flow. This tendency to hold more cash may be explained in the concept of investment cash flow sensitivity laid down by fazzari et al (1988). This tendency is the clear evidence that the Pakistani firms tends to invest in positive NPV projects from internal cash.

Cash volatility (cash volt) show in the random effect model assigns a very high significant and positive coefficient to cash flow volatility $(\mathrm{P}$-value $=0.000<0.05)$ this result is in alignment with the findings of opler et al (1999), The results are in conformity with the theory that firms tends to hold more cash when they are faced with uncertain time keynes (1936). The period of our analysis is the period of lot of economic uncertainty in Pakistan. Thus keeping on view these uncertainties Pakistani firms that are heavily dependent on their internal fund hold more cash out of there operational cash flow.

Leverage (lev) show in the random effect model assigns a negative and significant coefficient to leverage $(\mathrm{P}$-value $=0.01<0.05)$. Leverage is also turned as negative cash. The presence of leverage indicates the opportunity for the firms to obtain debt from external sources. Higher these sources, the less will be a need to hold more cash. Further increase in leverage increases the risk of bank corrupt, this risk adds to the volatility faced by the firms and they trend to hold more cash as it is evident from our cash flow volatility variables.

\section{Conclusion:}

In this study we argument the model proposed by Almeida at al (2004) with a variable of cash flow volatility (cash volt) and leverage (Lev). Where size and year effects were taken as control variables, the study revealed that the cash flow and cash flow volatility had a direct significant impact on firms cash holdings. However leverage tends to lower the cash holdings as firms having excess to external finance do not feel essential to hold more cash. These findings confirm one fact that Pakistani firms are heavily dependent on cash for their investment and precautionary needs. It is imperatives that the government must take steps to keep the economy stable so that firms will tend to invest more and hold less cash also credit to the firms must be kept at lower cost so that more and more firms can have access to it. This will lower the cash dependency of manufacturing firms.

\section{References}

[1] A.Minton, B., \& M.Schrand, C. (n.d.). The Impact of Cash Flow Volatility on Discretionary Investment and the Costs of Debt and Equity Financing.

[2] Armen Hovakimian, \& Hovakimian, G. (2005). Cash flow Senstivity of Investment: Firm Level Analysis.

[3] Bernadette A. Minton, C. S. (n.d.). The Impact of Cash Flow Volatility on Discretionary Investment and the cost of Debt and Equity Financing.

[4] Cleary, S. (2006). International corporate investment and the relationships between the financial constraints measure.

[5] Easterbrook, F. (1984). Two Agency-Cost Explanations of Dividends. American Economic Review vol.74, p.650-659.

[6] Froot, K., Scharfstein, D., \& Stein, J. (1993). Risk management: Coordinating corporate investment and financing policies. Journal of Finance vol.48, p. 1624-1658. 
[7] George Allayannis, B. R. (n.d.). Earnings volatility, cash flow volatility, and firm value.

[8] Graham, ,. J., \& Harvey, C. R. (2001). The theory and practice of corporate finance: Evidence from the field. Journal of financial economics 60, p.187-243.

[9] J. Campbell, D. D., \& Schwartz, W. (n.d.). Financing Constraints and the cost of capital: Evidence from the funding of corporate pension plans.

[10] Javad Moradi, H. V. (n.d.). Investigation the Effect of investment volatilities Sensitivity to Cash Flow in Listed Firms of Tehran Stock Exchange.

[11] Jean Paul Decamps, T. M. (2007). Free Cash flow, Issuance Costs and Stock Voltality.

[12] Jensen, ,. M. (1986). Agency Costs of Free Cash flow, Corporate Finance, and Takeovers. American Economic Review vol.76, p. 323329

[13] Klaas Mulier, K. S. (n.d.). Investment Cash Flow Sensitivity: The Role of Cash Flow Volatility" .

[14] Mairesse, J., \& Dormont, B. (1985). Labor and Investment demand at the firm level: A comparison of French, German and US manufacturing . p.1970-1979.

[15] Minton, B., \& Schrand, C. (1999). The Impact of Cash Flow Volatility on Discretionary Investment and the Costs of Debt and Equity Financing. Journal of Financial Economics vol.54, p.423-460.

[16] Modigiliani, F., \& M.H Miller. (1966). The Cost of Capital, Corporation Finance and the Theory of Investment.

[17] Saiyid S.Islam. (n.d.). Investment Cash Flow Sensitivity: International Evidence.

[18] Sehrish Ahsan, \& Ullah, N. (2013). Impact of Cash flow Volatility on Cash-Cash Flow Sensitivity of Pakistani Firms.

[19] Tao Chen, J. H. (2013). Financial Flexibility and Corporate Cash Policy 